\title{
Effects of Different Watering Intervals on Growth Performance of Abelmoschus Esculentus Presence with Super Absorbent Polymer Layer at the Root Zone with Moist Coir Dust Layers
}

\author{
T.N. Fernando ${ }^{1 *}$, A. G. B.Aruggoda ${ }^{2}$, S.A. Ariadurai ${ }^{3}$ and C. K. Disanayaka ${ }^{4}$ \\ ${ }^{1}$ Department of Agricultural Engineering and Machine Development, National Engineering Research and \\ Development Centre of Sri Lanka, Ekala, Ja-Ela \\ ${ }^{2}$ Department of Agricultural and Plantation Engineering, Faculty of Engineering Technology, The Open \\ University of Sri Lanka, Nawala, Nugegoda, Sri Lanka \\ ${ }^{3}$ Department of Textile and Apparel Technology, Faculty of Engineering Technology, The Open University of \\ Sri Lanka, Nawala, Nugegoda, Sri Lanka \\ ${ }^{4}$ Sri Lanka Atomic Energy Board, No. 60/460, Baseline road, Orugodawatta, Wellampitiya, Colombo
} 2373, Makurdi, Nigeria

*Corresponding Authors: T.N. Fernando, Department of Agricultural Engineering and Machine Development, National Engineering Research and Development Centre of Sri Lanka, Ekala, Ja-Ela

\begin{abstract}
Super Absorbent Polymers(SAP) isincreasingly being used for enhancing the water and nutrient use efficiencies in plants, creating a congenial and nourishing rhizospheric micro-environment for better plant growth and yield. Therefore, SAPs have been predominantly used in agricultural industry in recent past. The present experiment was conducted to assess the effects of different watering intervals on growth of Abelmoschus esculentus established in a potting media with SAP developed in Sri Lanka (SLSAP) as alayerat the root zone. Abelmoschus esculentus plants were established in pots added with potting mixture; sand, compost, top soil and burned paddy husk in the ratio of 1:1:1: 1/2 and the top layered with SLSAP as the middle, with moist coir dust layers from top and bottom. At 3, 5 and 7 days' intervals watered while maintaining the control at 3 days watering without adding SLSAP.Yield, plant height, numbers of flowers per plant, leaf area, moisture content in whole plant and relative humidity of plant leaves were measured. Except plant height, dates of watering were significant for all other measured parameter $(P<0.05)$. Also, watering at a 3 days' interval resulted in a good yield from Abelmoschus esculentus, prepared SLSAP added layer wise growth medium compared to plants grown in 3 days watering in control medium. Plants watered once in 7 days were observed to be wilted. However, adding water revived them showing no permanent wiling. Further, when frequency of watering was decreased from once in 3 days to 5 days and 7 days, growth parameters were reduced by certain percent.
\end{abstract}

Keywords: Super Absorbent Polymers, Layer wise medium, Watering intervals

\section{INTRODUCTION}

World population is increasing at an alarming rate and is expected to reach about nine billion by the end of year 2050 (FAO, 2009). On the other hand, food productivity is decreasing due to the effect of various abiotic stresses such as drought, salinity, heat and lack of nutrients. Therefore, minimizing these losses is a major concern of all nations in coping with the increased demand for food. With the present trend in agriculture in Sri Lanka, more people are inclined towards crop cultivation. This is practiced not only in villages, where farming is done as a profession, but also in highly urbanized communities where land space is limited and where the inhabitants lead busy lives. This is practiced generally, as an income earner and to save money by producing their own food. However, in certain instances the main impetus being recreation and relaxation. For sake of the concept of a greener environment and the necessity for preserving the environment for the future generations, planting along the streets and highways, landscaping and rooftop gardening are some of the main activities that need to be practiced. When it comes to maintaining healthy plants, under these circumstances, watering becomes the major issue. Water is essential for maintaining an adequate food supply and a productive environment for the human population and for other animals, plants and microbes worldwide. As human population and economies grow, global freshwater demand has been increasing 
rapidly (Hinrichsen et al., 1998, Postel, 1999, UNEP, 2003a and Gleick, 2004). Therefore, most countries employ practices to conserve existing water such as promote rainwater harvesting, restoring of ancient tanks and introduce crop irrigation systems etc. During dry seasons, long drought occurs in the arid zones. Problems associated with irrigation systems are water logging, over time, seepage from irrigation canals and irrigated fields causing water to accumulate in the upper soil levels, and water losses during pumping and transport. Further, approximately $60 \%$ of the water intended for crop irrigation never reaches the crop (Wallace, 2000). In the absence of adequate drainage, water tables rise in the upper soil levels, including the plant root zone, and crop growth is impaired. Such irrigated fields are sometimes referred to as "wet deserts" due to those being rendered unproductive (Pimentel et al., 2004). Further, in the urban areas, people are compelled to use purified drinking water for household crop cultivation and gardening, which is a waste of potable water and a costly exercise. Thus, it is apparent that water is a vital resource that needs to be conserved in the field of agriculture. There are many ways in which water conservation could be achieved, and one of which is the use of Super Absorbent Polymers (SAPs).

SAPs are structurally cross-linked, highly swollen and hydrophilic polymers, networks capable of absorbing a large amount of water or aqueous saline solutions, practically 10 to 1000 times of their original weight or volume in relatively short periods (Ramazani-Harandi et al., 2006). In the field of agriculture, one major purpose of using SAPs is to aid water sustenance and improve humidity condition of growth media. Further, SAPs are used to increase the water availability to the plant in the growth media, which would enable the plants to survive longer under water stress.Many researchers conducted studies to evaluate the performances of soil added SAP such as controlling soil erosion and runoff, increasing infiltration capacity, soil aggregate size, water retention capacity, survival of seedlings at droughts, nutrient recovery from applied fertilizers and Lengthening shelf-life of pot plants (Wallace and Wallance, 1986, 1990; Zhang and Miller, 1996; Johnson, 1984; Bres and Weston, 1993; Huttermann et al., 1999; Gehring et al., 1980; Smith andHarrison,1991; Bres and Weston, 1993; Taylor et al., 1986).The present study focused on introduction of developed SAP in Sri Lanka to cultivate crops under limited supply of water. The geographical area selected for the study is Colombo. Due to the highly polluted environment prevailing within the urban city limits, the temperature is raised, due to which in Colombo, during the daytime, the rate of soil water evaporation is high. This would result in wilting of plant leaves during daytime. Therefore, watering in the morning as well as in the evening is essential. However, frequent watering requires labour, money and time. People in the urban areas find it difficult to water continuously due to their busy life and costly water bills. Even with the lack of space for cultivation, urban people expect greenery in their surrounding as street plants, street gardens and green parks, which must be established with a possibility of variation such as annual and biannual planting methods. When maintaining those variations in cultivation, watering is an expensive process. Therefore, applying SAPs could be a good solution, as it would reduce the cost and lead to a better establishment of plants. Use of SAPs to maintain plants have been practiced in number of countries, including Vietnam, China and Iran in arid and semi-arid areas to overcome water scarcity.

SAPs were developed by Fernando et al., (2017) in Sri Lanka, processed by graft co-polymerization of acrylic acid on to the cellulose under the gamma irradiations for different applications in agriculture. This product named as Sri Lankan SAPs (SLSAPs). The Chemical structure of developed SLSAPs consists of cross-linked cellulose and neutralized poly acrylic acid grafted product. The characteristics showed that swelling ratios were 236-325 in distilled water. Highest water absorbency in neutral condition and too much acidity and alkalinity resulted in lower ratios of swelling. It had a highly porous structure, successful degradability in sandy loam soil within 70 days at a $29^{\circ} \mathrm{C}$ soil and $34^{\circ} \mathrm{C}$ atmospheric temperatures. Further, used sandy loam for the experimental is consisting of organic matter content, Electric conductivity $(\mathrm{Ec})$ and $\mathrm{pH}$ values $5 \%, 1.32 \mathrm{dS} / \mathrm{m}$ and 6.81 respectively. The $\mathrm{pH}$ and $\mathrm{Ec}$ values of sandy loam soil are such that it is suitable for mixing with developed SLSAPs. However, low organic matter content of sandy loam soil limits the growth of vegetable crops. Therefore, compost and other nutritional materials are required to be mixed with sandy loam soil. When compost and other fertilizers are mixed with soil, soil pH and Ec might be changed in the sandy loam soil. Furthermore, solutions with low concentration of urea and organic fertilizers could be mixed with SLSAPs (Fernando et al., 2017). In addition, some inorganic fertilizers of muriate of potash and tri super phosphate and hydroponic solutions are could not mixed with developed SLSAPs 
due to collapsing of the polymer (Fernando et al., 2013). The comparisons of above results point to a requirement of introduce a new cultivation medium with SLSAPs for cultivation of crops. The Fernando et al., (2017) introduced a new layer wise growth medium with SLSAP incorporated to cultivated crops.

The aim of present study was to identify the effects of different watering intervals on growth performance of Abelmoschus esculentus presence with Super Absorbent Polymer layer at the root zone with moist coir dust layers (prepared SLSAP added layer wise growth medium).

\section{Materials AND Methodology}

\subsection{Methodology}

The experiment was conducted in the plant house, which was established at the premises of the Open University of Sri Lanka, Nawala, Nugegoda. A layer wise growth medium was prepared as shown in Fig. 1. When preparing the layer wise growth medium, the neutralize condition of developed SLSAP and degradation characteristics in soil and coir dust media were considered as mentioned in Fernando

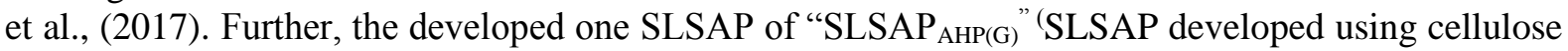
extracted from Alkaline Hydrogen Peroxide (AHP) pre-treatment and Gamma(G) irradiation)was prepared for the experiment by following the procedure described in Fernando et al., (2017).

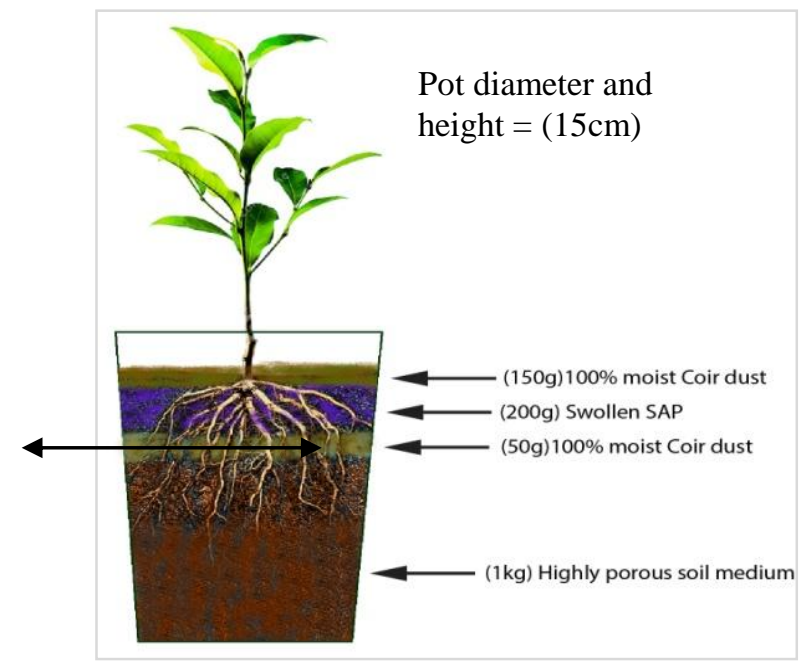

Fig1. Prepared layer-wise growth medium (Fernando et al., 2017)

Well neutralized highly porous soil medium was prepared by mixing sand, compost, top soil and burned paddy husk in the ratio of $1: 1: 1: 1 / 2$ and mixed with a recommended quantity of inorganic fertilizers. Highly porous soil medium was moist up to field capacity prior to cultivation. Field capacity is the condition where maximum amount of water possible is available for the plant. Volume of water required for moisture in soil to be raised to field capacity was measured using pressure plate as described in Fernando et al., (2014) and Fernando et al., (2013 a). Abelmoschus esculentus seeds were sworn in a nursery in a month prior to start the experiments. Four weeks old seedlings were transplanted to pots(one seedling per pot). 3 days after transplanting, swollen SLSAP AHP(G) $_{\text {to }}$ the middle and $100 \%$ moist coir dust from top and bottom were established as layers (Figure 1). Control treatment was added with 100\% moist coir dusts only (without SAP). The weight of SAP always similar to the $100 \%$ moist coir dust, which was added between the two layers (up and down) of coir dust in control. 3, 5 and 7 days watering intervals carried out for a period of $31 / 2$ months. Treatments were replicated three times and arranged Completely Randomized Design (CRD).

$\mathrm{T} 1 \quad$ - 2kg Soil + (100g Coir dust $+400 \mathrm{~g}$ coir dust $+300 \mathrm{~g}$ Coir dust $)+3$ days

$$
800 \mathrm{~g} 100 \% \text { moist coir dust }
$$

(3 days/Control)

T2 - 2kg Soil + (100g Coir dust +400 g SAP $+300 \mathrm{~g}$ Coir dust $)+3$ days

T3 - $2 \mathrm{~kg}$ Soil $+(100 \mathrm{~g}$ Coir dust $+400 \mathrm{~g} \mathrm{SAP}+300 \mathrm{~g}$ Coir dust $)+5$ days

T4 - 2kg Soil + (100g Coir dust +400 g SAP $+300 g$ Coir dust $)+7$ days 
During the period of growth, constant weights of growth medium in all pots were maintained. Additional pots were maintained without plants to measure volume of water applied in each day. Pots were weighed during the time of watering. Lost water was replenished to maintain constant weight of growth medium during the period of growth (Details of calculation of total weight lost in each pot were mentioned in appendix 1). After $31 / 2$ months, growth parameters such as plant height was measured from collar region to the apex at harvesting $(\mathrm{cm})$, leaf area of five $(05)$ randomly selected mature leaves from a plant was measured using a measuring scale $\left(\mathrm{cm}^{2}\right)$.Yield $(\mathrm{g})$ and moisture content of whole plant were measured after oven drying to a constant weight at $60{ }^{\circ} \mathrm{C}$. Relative Water Content (RWC) and moisture content were measured one week after, watering was stopped.

RWC was determined using the following formula;RWC $=\frac{((\mathrm{FW}-\mathrm{DW}))}{(\mathrm{TW}-\mathrm{DW})}(1)$ where, FW=Fresh weight of plant leaves, DW=Dry weight of plant leave, TW=Turgid weights of plant leaves.

In addition, relative humidity and day temperature were measured daily during the period of growth using wet and dry bulb thermometer (hygrometer), which was placed inside the plant house in order to study the general climatic changes in the area.

When nutrient deficiency problems were prominent, the same amount by volume of foliar fertilizer was applied to each plant. In addition, when plants began to turn yellow $1 \%$ urea solution was added to the water which was being applied. Further, during flowering and fruiting stage fermented cattle manure and leaves and wormy wash were added by mixing them in the applied water once every two weeks as described in Fernando et al., (2013b). Pests were controlled only when the infestation was seen to be a threat to normal plant growth. Hand weeding was done when necessary.

The data were analyzed using the statistical software of ANOVA 16 version. factors were tested at probability 0.05 value of significance.

The considering of analysed data, the relationship of variation of growth parameters with watering once in 3 days, 5 days and 7 days with the control treatment (3days/C) were evaluated to find out best performed treatment. In addition, the variation of growth parameters with best performed treatment were evaluated also.

\section{RESULTS AND DISCUSSION}

Table 1 shows the variation of the probability values of measured parameters. Except plant height, dates of watering were significant for other measured parameter $(\mathrm{P}<0.05)$. Variations of mean values of yield, plant height, number of flowers per plant and leaf area, moisture content of whole plant and RWC of plant leaves were showed in Fig. 2 (a-d). All measured growth parameters were highest in plants watered once in 3 days in SLSAP incorporated layer wise medium compared to those of plants that were watered once in 3 days in the $100 \%$ moist coir dust added medium ( 3 days/C). Further, results of moisture content of whole plant and RWC of plant leaves in SAP added 3 days after watering medium consisted highest amount of water compared to 3 days/C at the average environment conditions of average temperature $33^{\circ} \mathrm{C}$ and relative humidity $55 \%$ in the research area. Furthermore, when frequency of watering was decreased from once in 3 days to 5 days and 3 days to 7 days, growth parameters were reduced by certain percentages, as indicated in Table 2 . The results in Table 2 shows that drastic yield losses in watered media after 5 days and 7 days compared with plants treated in the medium of SAP added 3 days after watering. However, lower relative percentage weight losses of moisture content and RWC in plants watered at 5 days and 7 days watering intervals were observed when compared with those of plants watered at a 3 days' interval with SAP. The reason was low height of plants requiring less water for growth without permanent wilting (Fig. 3). Plants watered once in 7 days were observed to be wilted. However, adding water revived them showing no permanent wiling. Further, when frequency of watering was decreased from once in 3 days to 5 and 7 days, growth parameters were reduced by certain percent in SAP incorporated media.The average volume of water applied was approximately $205 \mathrm{ml}, 150 \mathrm{ml}, 250 \mathrm{ml}$ and $400 \mathrm{ml}$ at 3 days $/ \mathrm{C}, 3$ days, 5 days and 7 days' intervals respectively. Further, quantity of water replenished at each watering interval varied due to the condition of environment. During days with high humidity, (rainy days) low volumes of water were used.

Table1. Variation of growth parameters of Abelmoschus esculentus

\begin{tabular}{|l|l|l|l|l|l|l|}
\hline Growth & yield & Plant height & No. of & Leaf area & Moisture & RWC \\
\hline
\end{tabular}




\begin{tabular}{|l|l|l|l|l|l|l|}
\hline parameters & & & flowers & & $\begin{array}{l}\text { content of } \\
\text { whole plant }\end{array}$ & \\
\hline $\begin{array}{l}\text { Probability } \\
\text { values }\end{array}$ & 0.000 & 0.141 & 0.000 & 0.000 & 0.000 & 0.004 \\
\hline
\end{tabular}

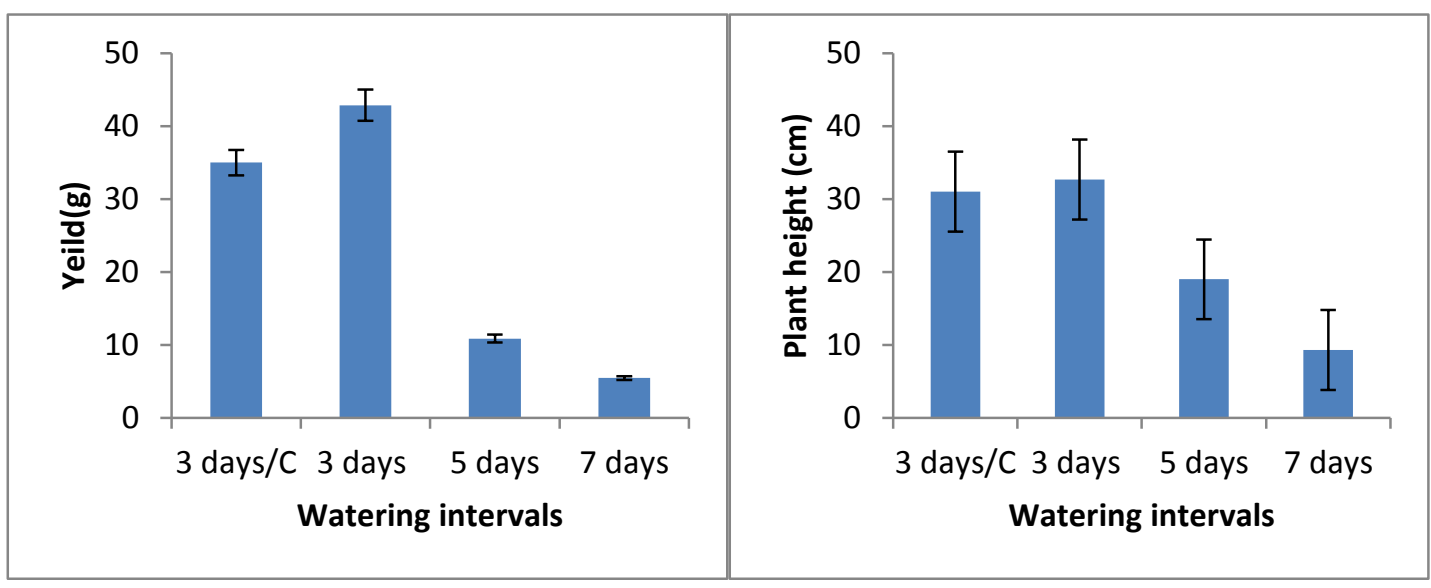

(a)Variation of mean of yield

(b) Variation of mean of plant height

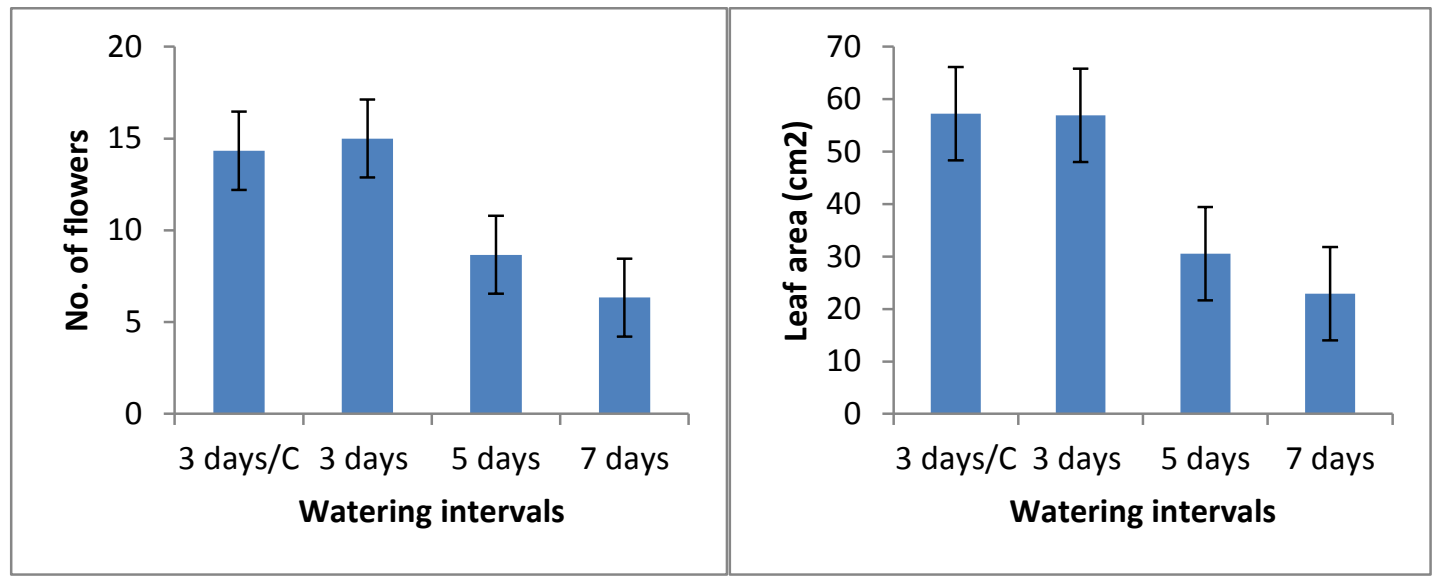

(c) Variation of mean of No of flowers

(d) Variation of mean of leaf area

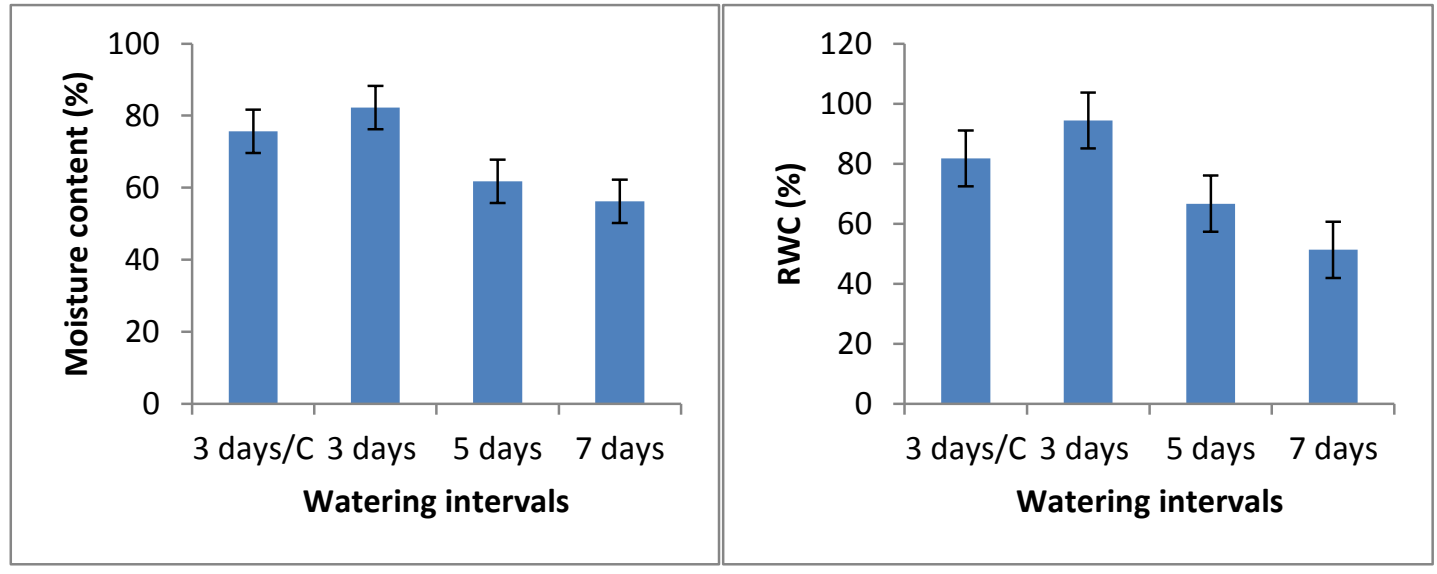

(e) Variation of mean of Moisture cont.

(f) Variation of mean of RWC

Fig2. Variation of mean values of growth parameters of Abelmoschus esculentus

Table2: Percentage of losses of growth parameters of Abelmoschus esculentus relative to watering comparison with plants in medium of SLSAP added 3days watering

\begin{tabular}{|l|l|}
\hline Watering & Growth parameters \% \\
\hline
\end{tabular}


Effects of Different Watering Intervals on Growth Performance of Abelmoschus Esculentus Presence with Super Absorbent Polymer Layer at the Root Zone with Moist Coir Dust Layers

\begin{tabular}{|l|l|l|l|l|l|l|}
\hline intervals & Yield $(\mathbf{g})$ & $\begin{array}{l}\text { Plant height } \\
(\mathbf{c m})\end{array}$ & $\begin{array}{l}\text { No. of } \\
\text { flowers }\end{array}$ & $\begin{array}{l}\text { Leaf area } \\
\left.\mathbf{c m}^{2}\right)\end{array}$ & $\begin{array}{l}\text { Moisture } \\
\text { content of } \\
\text { whole plant }\end{array}$ & RWC \\
\hline $\mathbf{5}$ days & 54.05 & 22.41 & 21.11 & 23.92 & 10.22 & 13.05 \\
\hline $\mathbf{7}$ days & 63.18 & 38.25 & 28.89 & 17.57 & 12.96 & 20.31 \\
\hline
\end{tabular}

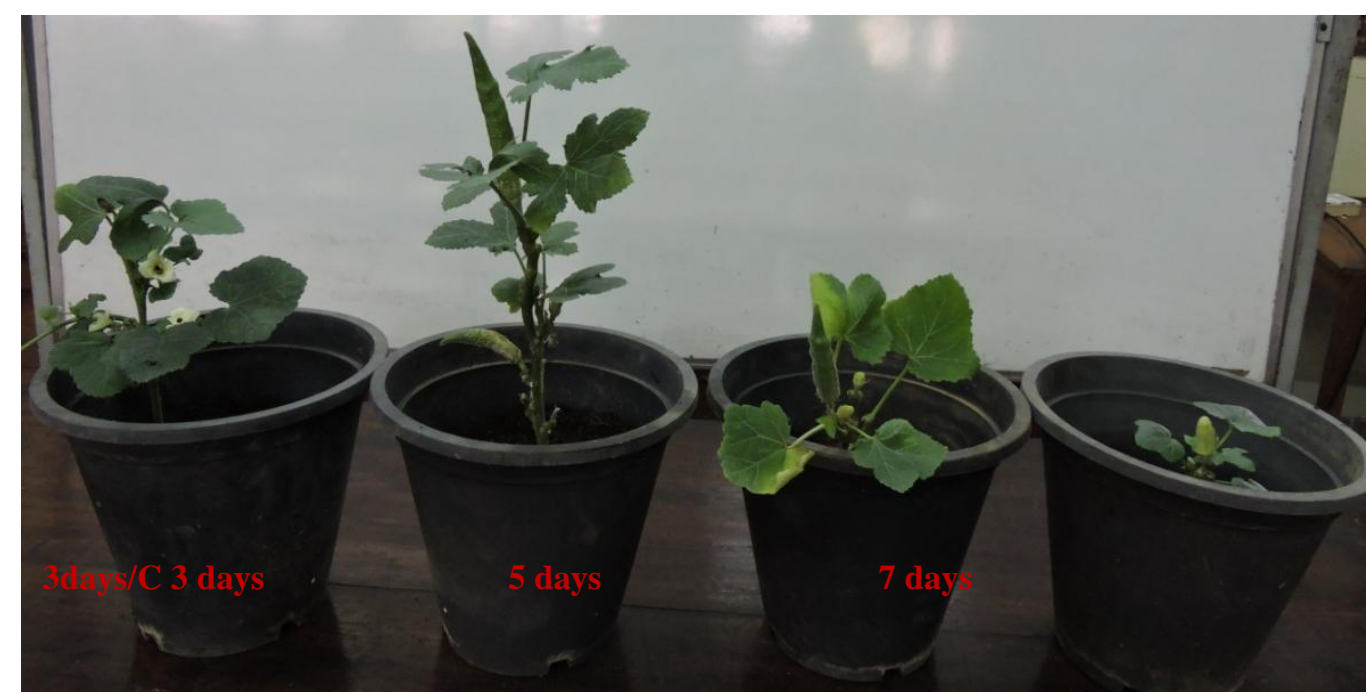

Fig3. Visual observation of Abelmoschus esculentusafter 3 months

The results of present study are in line with the findings of Yazdani et al., (2007). They have reported that the yield, harvesting index, canopy height, total dry weight, number of flowers per plant, leaf area and crop growth rate increased when irrigation interval was 6 days compared to results obtained with intervals of 8 and 10 days. Also, Ghasemi et al., (2008) where it has been reported the best amount of super absorbent $(0,0.2,0.4,0.6,0.8$ and $1 \%$ of weight $)$ in different irrigation intervals $(2,3,4$ and 5 days) for the plant Chrysanthemum morifolium. According to their findings, using hydrophilic gels had positive and significant effect on number of flowers per plant, area of leaves, plant height, root/shoot proportion and coverage area in drought stress and the best performance in all in dices was related to $0.8 \%$ treatment compared to control (without SAP) and water deficit reduces growth parameters However, results of the present study indicated that the growth environment of SLSAP incorporated and incorporated watering treatments of once in 3 days interval may result in good yield when compared to results with other watering intervals due to moisture retaining ability of incorporated SLSAP.

\section{CONCLuSion}

The results of the present study indicated that watering at a 3 days' interval resulted in a good yield from Abelmoschus esculentus, which were grown in SLSAP added layer wise growth medium compared to plants grown in 3 days/C medium. Plants watered once in 7 days were observed to be wilted. However, adding water revived them showing no permanent wiling. Further, when frequency of watering was decreased from once in 3 days to 5 and 7 days, growth parameters were reduced by certain percent in SLSAP incorporated growth media.

\section{REFERENCES}

[1] Bres W and Weston L.A., (1993). Influence of gel additives on nitrate, ammonium and water retention and tomato growth in a soilless medium, Journal of Hortic.Sci., 28: 1005-1007(abstract).

[2] Fernando T.N, Ariadurai S.A, Disanayaka C.K, KulathungeS and Aruggoda A.G.B, (2017). Development of Radiation Grafted Super Absorbent Polymers for Agricultural Applications, Journal of energy procedia, Elsevier, vol.127.PP 163-177.

[3] Fernando T.N, Aruggoda A.G.B, Disanayaka C. K and Kulathunge S., (2014). Evaluating the effects of different watering intervals and prepared soilless media incorporated with a best weight of Super Absorbent Polymer(SAP) on growth of tomato, Journal of Engineering Technology, the Open University of Sri Lanka, vol.2 No.2 pp14:1-14. 
[4] Fernando T.N, Aruggoda A.G.B, Dissanayaka C.K and Kulatunga S, (2013a). Effect of Super Water Absorbent Polymer and Watering Capacity on Growth of Tomato (Lycopersiconesculentum Mill), Journal of Engineering Technology, The Open University of Sri Lanka, vol.1 No.2 pp14:1-14.

[5] Fernando T.N, Aruggoda A.G.B, Disanayaka C. K and Kulathunge S., (2013b). Study the Effect of Different Levels of Super Water Absorbent Polymer (SWAP) and organic solutions on Growth of Pak-Choi (Brassica rapa) under Soil less culture in urban Agricultural practices, the international conference of agriculture and animal science. Pp 13:85-97.

[6] FAO.org, (2009). How to Feed the World in 2050, Available at: http://www.fao.org/fileadmin/templates/wsfs/docs/expert_paper/How_to_Feed_the_World_in_2050.pdf. [Accessed 7 December 2016].

[7] Gehring J.M and Lewis A.J., (1980). Effect of polymer on wilting and moisture stress of bedding plants, Journal of Am. Soc. Hort. Sci., 105:511-513.

[8] Ghasemi M and Khushkhui M., (2008). Effects of super absorbent polymer on irrigation interval and growth and development of Chrysanthemum (Dendranthema grandiflorumkitam), Journal of Sci. Technol. Iran, 8(2): 65-82.

[9] Gleick P.H., (2004). Global freshwater resources: Soft-path solutions for the 21st century, Journal of Science, 302: 1524-1528.

[10] Hinrichsen D, Robey B,Upadhyay U.D., (1998). Solutions for a Water-short World, Baltimore: Johns Hopkins School of Public Health, Population Information Program. Population Reports, series M, No. 14.

[11] Huttermann A, Zommorodia M, Reise K., (1999). Addition of hydrogel to soil for prolonging the survival of pinsha lepens is seedlings subjected to drought, Journal of Soil Till.Res., 50: 295-304.

[12] Johnson M.S., (1984). The effect of gel forming polyacrylamides on moisture storage in sandy soils, Journal of Sci. Food Agric., 35: 1196-1200.

[13] Pimentel D, Berger B, Filiberto D, Newton M, Wolfe B, Karabinakis E, Clark S, Poon E, Abbett E and Nandaopal S., (2004). Water resources, agriculture, and the environment, Ithaca (NY): New York State College of Agriculture and Life Sciences, Cornell University. Report 04-140.

[14] Postel S., (1999). Pillar of Sand: Can the Irrigation Miracle Last, New York: W.W. Norton.

[15] Ramazani-Harandi M. J, Zohuriaan-Mehr M.J, Yousefi A.A, Ershad- Langroudi A and Kabiri K., (2006). Rheological determination of the swollen gel strength of superabsorbent polymer hydrogels, Journal of Polymer Testing, 25, 470-474.

[16] Smith J.D and Harrison H.C., (1991). Evaluation of polymers for controlled release properties when incorporated with fertilizer solutions, Communications in soil science and plant analysis, 22, 559-573.

[17] Taylor K .C and Halfacre R. G., (1986). The effect of hydrophilic polymer on media water retention and nutrient availability to Ligustrum lucidum, Journal of Hort.Sci., 21, 1159-1161.

[18][UNEP] United Nations Environment Programme, (2003a). Water scarcity in the Middle East-North African region, General Assembly Resolution 53-21. Available at: www.skmun.freeservers.com/unep/unepres1.htm.

[19] Wallace A and Wallance G.A., (1986). Control of soil erosion by polymeric soil conditioners, Journal of Soil science, 141, 363-367.

[20] Wallace A and Wallance G.A., (1990). Interactions encountered when supply nitrogen and phosphorus fertilizer and a water soluble polyacrylamide to soil, Journal of Plant Nutr., 13:3-4,343-347.

[21] Wallace J.S., (2000). Increasing agricultural water use efficiency to meet future food production, Agriculture, Ecosystems and Environment, 82: 105-119.

[22] Yazdani F, Allahdadi I and Akbari G.A., (2007). Impact of super absorbent polymer on yield and growth analysis of soybean (Glycine max L.) under drought stress condition, Journal of Biol. Sci., 10:4190-4196.

[23]Zhang X.C and Miller W.P., (1996). Polyacrylamide effect on infiltration and erosion furrows soil science, Journal of American, 60, 866-872.

Citation: T.N. Fernando, et.al., (2021). "Effects of Different Watering Intervals on Growth Performance of Abelmoschus Esculentus Presence with Super Absorbent Polymer Layer at the Root Zone with Moist Coir Dust Layers". ", International Journal of Research Studies in Agricultural Sciences (IJRSAS), 7(5), pp. 1117. DOI: http://dx.doi.org/10.20431/2454-6224.0705002

Copyright: (C) 2021 Authors. This is an open-access article distributed under the terms of the Creative Commons Attribution License, which permits unrestricted use, distribution, and reproduction in any medium, provided the original author and source are credited. 